\title{
EMBARAÇO, HUMILHAÇÃO E \\ TRANSPARÊNCIA PSÍQUICA: O TÍMIDO \\ E SUA DEPENDÊNCIA DO OLHAR
}

Julio Verztman

\author{
Julio Verztman \\ Professor do \\ Programa de \\ Pós-Graduação em \\ Teoria Psicanalítica \\ IP-UFRJ; \\ coordenador do \\ Núcleo de Estudos \\ em Psicanálise \\ e Clínica da \\ Contemporaneidade \\ (Nepecc); \\ psiquiatra do Ipub- \\ UFRJ.
}

RESUMO: Pretende-se discutir os impasses experimentados pelo sujeito caracterizado como tímido na sua relação com o olhar. Formulou-se a hipótese de que a vergonha - emoção central do tipo de subjetividade de que iremos tratar — é neste contexto vivida como embaraço, humilhação ou transparência psíquica. Sugerimos que a incidência do olhar exporá certas fragilidades narcísicas quanto à construção de barreiras que protejam o campo da interioridade. Apresentaremos ao longo do texto os principais aspectos do embaraço, da humilhação e da transparência psíquica, utilizando vinhetas clínicas retiradas de uma pesquisa clínica.

Palavras-chave: Vergonha, timidez, narcisismo, olhar, clínica contemporânea.

ABSTRACT: Embarrassment, humiliation and transparency: The shy subject and his/her dependence on the gaze. The main goal of this article is to examine shy individuals and their troublesome experiences concerning gaze. A clinic psychoanalytical research on social anxiety disordered patients (social phobia) revealed that shame in this context is also endured as embarrassment, humiliation and psychic transparency. This work suggests that they carry a frail narcissistic development and therefore are unable to protect their psychological inner selves. Features of embarrassment, humiliation and psychic transparency can be found through various clinical examples. Additionally, the recent analysis on shame implies a new individual scope in contemporary society.

Keywords: Shame, shyness, narcissism, gaze, contemporary clinical psychoanalysis. 
$\mathrm{R}$ efletiremos, aqui, sobre algumas características do sujeito cuja principal queixa gravita em torno da timidez — exatamente aquele que fica paralisado diante do paradoxo de ser supervisível ou de ser invisível, de ter uma atitude voyeurista ou exibicionista diante do outro, de ser invadido pela mirada de qualquer um ou de ser completamente opaco a ela, de nunca poder ser visto a partir do ângulo correto. Este sujeito expressa de modo paradigmático o sentimento de insuficiência narcísica diante do olhar, insuficiência articulada a um grau intenso de dependência. O dito tímido depende em larga medida de um olhar privilegiado para ter acesso aos principais parâmetros a respeito de si mesmo. Nosso intuito é discutir sobre as vicissitudes desse olhar, sobre a relação de dependência nele implicada e sobre algumas formas pelas quais essa dependência se estabiliza e se constrói. Em função de alguns fatores da cultura atual (EHRENBERG, 1998; GIDDENS, 2002; GOULEJAC, 1996; VERZTMAN, 2005; PINHEIRO, VERZTMAN, VENTURI \& BARBOSA, 2006), tais como o esvaziamento de alguns predicados subjetivos correlacionados a ideais coletivos, a dificuldade de se relacionar com o desejo do outro através de uma atitude interpretativa, ou mesmo os limites contemporâneos para construir uma atividade imaginativa que prescinda do referente à fisicalidade, o olhar se torna o ponto de partida e o ponto de chegada da atitude avaliativa sobre si mesmo e sobre o outro.

Procurarei, ao longo do texto, demonstrar que os sujeitos implicados em nossa investigação encontram saídas vacilantes para impasses na dinâmica do olhar, pagando o preço do embaraço, da humilhação ou da transparência psíquica. Muitas vezes essas três características podem ser observadas em conjunto, embora o mais comum seja a conjugação da sensação de transparência com uma das outras duas. Esta reflexão tem como base uma pesquisa clínica realizada pelo Núcleo de Estudos em Psicanálise e Clínica da Contemporaneidade (Nepecc, www.psicologia.ufrj. br/nepecc), coordenado por Teresa Pinheiro, Regina Herzog e Julio Verztman, acerca do atendimento psicanalítico a pacientes que apresentam o diagnóstico psiquiátrico de fobia social. Sugiro a consulta ao material já produzido por este núcleo de pesquisa (VERZTMAN, 2005; PINHEIRO, VERZTMAN, VENTURI \& BARBOSA, 2006; VERZTMAN, HERZOG \& PINHEIRO 2010; VERZTMAN, HERZOG, PINHEIRO \& FERREIRA, 2012; VENTURI \& VERZTMAN, 2012) para que o leitor possa se familiarizar com o uso do referido diagnóstico psiquiátrico na aproximação com o tema da timidez. Utilizamos as palavras tímido ou timidez apenas para nomear uma característica presente em todos os pacientes atendidos por nossa equipe. Este termo foi pinçado de seus discursos porque respeita um modo de autodesignação no que tange a uma qualificação de si mesmo e de seus sintomas.

“Tímido” ou "timidez” não descrevem um universo psicopatológico restrito que faça sentido para a psicanálise. Este sujeito que se queixa de timidez, 
entretanto, nos oferece elementos importantes para estudarmos questões narcísicas relacionadas à problemática do olhar e às suas formas de dependência.

É necessário, antes de tudo, informar que chegamos a este universo teóricoclínico a partir de um estudo anterior sobre a vergonha. Partindo da sugestão freudiana presente em Luto e melancolia (FREUD, 1917/1993), segundo a qual o melancólico é capaz de afirmar as piores coisas de si sem experimentar esta emoção, nos servimos de autores pós-freudianos de correntes heterogêneas (CICCONE \& FERRANT, 2009; GREEN, 2003; MILLER, 2003; TISSERON, 1992; ZYGOURIS, 1995), a fim de explorar os aspectos narcísicos da vergonha (VERZTMAN, 2011). O que se segue está em continuidade com esta discussão.

\section{AS VIZINHANÇAS EMOCIONAIS DA VERGONHA}

No projeto-piloto desta pesquisa, que envolveu o atendimento a apenas dois pacientes com o diagnóstico de fobia social — antes da oferta de atendimento aos demais - duas possibilidades de experiência da vergonha chamaram a atenção: a vergonha vivida como embaraço e a vergonha vivida como humilhação. O paciente 1 (vergonha como embaraço) conseguia nomear alguns de seus medos diante da exposição ao olhar do outro, conseguia evitar situações nas quais poderia sentir vergonha. O motivo de sua vergonha lhe escapava inteiramente, e não percebia qualquer animosidade intencional no outro, mesmo que isto fosse constantemente temido. O paciente 2 (vergonha como humilhação), ao contrário, era muito mais retraído, desconfiado, não conseguia sequer definir o que sentia e se precavia permanentemente da possibilidade palpável de sofrer humilhação intencional por parte do outro. Para a distinção entre embaraço e humilhação, seguiremos alguns apontamentos de De La Taille (2002). Este autor, pesquisador no campo da psicologia do desenvolvimento moral nos fornecerá parâmetros descritivos relevantes para nossa discussão.

\section{EMBARAÇO}

Em português e em francês (mas não em inglês) há certa sobreposição entre vergonha e embaraço, mas mesmo assim há diferenças importantes. O embaraço em geral é considerado a vertente menos intensa e judicativa do universo semântico da vergonha. O embaraço é a sensação de desconforto que ocorre quando alguém se sente exposto (DE LA TAILLE, 2002, p.75-76). Ele denuncia os sofrimentos correlacionados com toda a trama relacional da exposição, tais como estar na posição de objeto, não ter qualquer controle sobre o que está sendo visto, sofrer as consequências da passividade diante do outro, suportar com dor a reflexividade própria da relação com o olhar do outro, entre outros fatores. 
O desconforto com a exposição, entretanto, é um aspecto comum entre a vergonha e o embaraço:

“Longe de ser mera questão de definição, veremos que o sentimento de vergonha decorrente do simples ‘ser objeto para outrem' (e não somente do ‘ser objeto desprezado por outrem') é importante para compreender o referido sentimento, notadamente no seu desenvolvimento durante a infância.” (DE LA TAILLE, 2002, p.77)

O simples fato de se sentir objeto do olhar de alguém pode produzir este sofrimento, mesmo que o olhar alheio não traga um juízo negativo. Este é um aspecto fundamental para o que caracterizamos em nossa pesquisa como o tímido embaraçado. Ele procura permanentemente antecipar o perigo do julgamento negativo e, assim, do desprezo alheio, através de uma forma particular e crônica de angústia (PACHECO-FERREIRA, 2012). Caso contrário, o permanente embaraço se tornaria vergonha inconsolável. Isto porque, em comparação com a vergonha, do ponto de vista moral o embaraço não ocupa papel relevante. A vergonha é um passo adiante do embaraço, já que aí ser objeto do olhar de outrem equivale a ser objeto de desprezo de outrem.

De la Taille sugere que o embaraço é uma forma muito antiga de experiência da vergonha. O autor demonstra a indissociabilidade entre consciência de si, consciência da própria perceptibilidade e embaraço como sofrimento produzido pela exposição. O embaraço testemunha aquilo que não é assimilável como perfeição narcísica no desenvolvimento da criança. No processo de separação da alteridade que consolida a estabilização da imagem narcísica, o perigo de ser tomado como objeto do olhar alheio vai se conjugando a outros perigos: ser malvisto e, consequentemente, deixar de ser objeto de estima do outro. O papel do ambiente é fundamental para que estes perigos não sejam negados, ao menos como perigos potenciais, mas também não se tornem ameaçadores a ponto de paralisar o infante no seu gesto espontâneo. É neste sentido que Ciccone e Ferrant (2009) propõem uma diferença entre vergonha experimentada e vergonha sinal de alarme:

"Numa primeira aproximação, a vergonha sinal de alarme pressente a analidade, a confusão e a ferida narcísica como consequência do risco de perda de amor do objeto. Como sublinhamos, ela veicula a memória afetiva das falhas parciais da afinação entre o sujeito e seu ambiente, ao mesmo tempo que uma saída possível se apoia nesse mesmo ambiente. Nesse tipo de situação atravessada por todos os seres humanos, o fato de ser pequeno, dependente e correndo o risco de desamparo, é constantemente tratado e cuidado pelas capacidades continentes de um ambiente suficientemente atento e atencioso. A vergonha sinal de alarme veicula também os fracassos parciais da aprendizagem da higiene, do controle esfincteriano e de todas 
as falhas da continência corporal. Essas inevitáveis feridas narcísicas são tratadas ao longo do tempo - mesmo sem serem nunca completamente ultrapassadas — pela colocação em jogo dos autoerotismos e dos processos de interiorização das funções de salvaguarda atribuídas, de início, ao objeto.” (CICCONE \& FERRANT, 2009, p.61-62. Tradução livre)

Voltando à nossa discussão anterior, podemos dizer que o embaraço, o qual estamos associando à vergonha sinal de alarme - é um desconforto relacionado ao disparo de um sistema de alarme que mobiliza o psiquismo a se proteger contra feridas que atingiriam o domínio narcísico. Estamos aqui supondo que o embaraço é a parte deste sistema que limita a exposição e a impede de se tornar uma exposição que contraria a imagem idealizada — ou ao menos aceitável — de si. Dessa forma, o embaraço implica um tipo de sofrimento cujo referente não é o rebaixamento da autoimagem, fruto do julgamento alheio, própria das experiências mais típicas de vergonha consumada. O embaraço é a antecipação da vergonha. É a percepção do perigo de sentir vergonha, é uma proteção contra a vergonha. Para que estas "funções de salvaguarda” diante do embaraço — para retomar a expressão de Ciccone e Ferrant — possam se efetivar, é imprescindível o papel do objeto. É o objeto que vai alçar a um futuro indeterminado ou a uma hipótese presente, mas longínqua, a ameaça de expulsão subjetiva que as experiências mais intensas de vergonha encerram.

Não sabemos ao certo os motivos, mas a clínica dos ditos 'tímidos' nos coloca diante da suposição de que pode haver hipertrofia do embaraço. Nesse caso, a ameaça da vergonha é tão presente e, ao mesmo tempo, tão pouco inserida em qualquer narrativa ou aspecto integrado do psiquismo, que a vida gira em torno de antecipar e prevenir sua emergência. Há um verdadeiro curto-circuito entre exposição e vergonha, entre o alarme e sua consumação, o qual tem como pano de fundo a fragilidade da proteção proporcionada pelo ambiente. Sempre que o sujeito se expõe a um perigo que não consegue nomear, ou seja, o perigo de vir a sentir uma vergonha irreparável, o simples contato com o olhar do outro que enuncia tal ameaça o paralisa e o empurra para a solidão, um dos contextos capazes de lhes assegurar proteção.

Alguns pacientes nos permitem um vislumbre deste tipo de vivência. O sentimento de vergonha nas relações sociais costuma ser a principal queixa. Uma paciente relata que não gosta de andar na rua ou de ônibus. Não gosta de andar de ônibus porque quando se senta, sabe que as pessoas do outro lado podem vê-la, e fica, neste momento, terrivelmente exposta. Revela o temor de que pensem algo negativo a seu respeito, embora não saiba dizer muito claramente o que elas possam pensar. Suas fantasias quanto ao olhar do outro podem apresentar caráter persecutório, mas estas são pouco elaboradas. Diz apenas que podem 
achar que ela tem “cara de boba” ou que é "magrinha”. Imagina com angústia poder, por qualquer motivo, vir a fazer uma cena ridícula, como, por exemplo, levar um tombo e ser motivo de riso. Esforça-se permanentemente para não chamar a atenção alheia de nenhuma maneira, mas sabe que este esforço é infrutífero. Há uma afinidade natural entre si e o olhar invasivo de quem a circunda.

É frequente que esses sujeitos tenham poucas lembranças de infância. Outra paciente, por exemplo, não sabe dizer quando começou a se sentir envergonhada, afirmando que “sempre foi assim”. Após algum tempo de análise, ela propôs uma origem para seu sentimento excessivo de estar exposta. Certa época, já adolescente, passou a ter que almoçar fora de casa. Foi muito difícil ter que pedir sua própria comida. Estava acostumada ao fato de sua mãe sempre ter providenciado isso por ela. Este breve momento de separação da mãe disparou nesta paciente um sinal de alarme para o perigo de rejeição por parte de qualquer um que cruzasse o seu olhar. Os fatos mais banais eram vividos com ansiedade, ruborização e medo, contando como certo que, na sua fantasia pudessem ser observados por terceiros. Quando discutirmos o tema da transparência psíquica, voltaremos às peculiaridades deste tipo de relação intersubjetiva com a mãe.

Por ora, ressaltamos o embaraço permanente vivido pela paciente quando está fora do alcance do olhar materno. Não supõe nenhuma animosidade clara por parte do outro anônimo que "teima” em avaliá-la; todavia, teme ser tomada por inadequada ou ridícula a qualquer momento. Desenvolve a estratégia de antecipar todos os ângulos nos quais a visão incidiria sobre ela, mas sua incapacidade de construir uma barreira ao que será visível mantém seus sistemas de alarme excessivamente sensíveis.

O embaraço, a princípio medida protetora no que tange a ameaças ao domínio narcísico, se torna um sofrimento permanente para certos tímidos. Este sofrimento é a marca de uma relação com o objeto construída sobre a impossibilidade de prescindir de seu olhar. Estar longe — geralmente do olhar materno - é estar em perigo. Um perigo desconhecido quanto à sua fonte e seu modo de operar. As estratégias criadas para tornar a vida suportável são: permanecer em estado de alerta — vivido como embaraço — ou estar ao abrigo do olhar privilegiado já descrito. Autores como Mc Dougall (1992), com sua descrição do amor materno fusional; Pontalis (1991), através de sua metáfora sobre um tipo de possessão subjetiva que exerce sua dominação a partir de dentro; e Aulagnier (1990), com sua bela proposição de direito ao segredo como condição de pensar, nos fornecem subsídios para compreender um tipo de relação com o objeto materno pautada numa atitude invasiva. 


\section{HUMILHAÇÃO}

A humilhação, em seu sentido forte, implica o sentimento de ser rebaixado pelo outro. O ato de rebaixar ou o sentimento de ter sido rebaixado produzem a frequente articulação entre vergonha e humilhação. Na vergonha, como vimos, o sujeito se sente rebaixado diante de seus ideais. É uma emoção que pode ser desencadeada quando qualquer membro da comunidade, o qual, aos olhos do sujeito, encarna ou sustenta esses ideais, testemunha a sua queda. Este outro é somente a testemunha, frisamos. A vergonha ocorrerá mesmo que o outro sequer perceba os motivos que levaram o sujeito a ter que se esconder da sua mirada. Ela pode acontecer ainda quando o outro não tem qualquer julgamento negativo em relação a tal imagem. Como já dissemos, na vergonha o outro é apenas o depositário de uma projeção narcísica desvalorizada; ela é o resultado de uma operação na qual o que está em jogo é: o que eu sentiria se pudesse me ver do lugar a partir do qual o outro me vê? Assim, ela é uma emoção referida ao campo do narcisismo porque o olhar do outro tem pouca relevância nesta relação de si a si. O que toma a cena é a maciça projeção sobre este olhar.

Desse modo, uma das condições para que a vergonha se desencadeie é a plausibilidade dessa projeção, ou seja, deve existir alguma afinidade entre a minha projeção e o modo como minha imagem é recebida. Tal plausibilidade se organiza geralmente sobre traços amplos e vagos. O principal deles diz respeito ao fato de o outro ser um membro da comunidade, que acredita nos mesmos valores que o sujeito envergonhado contrariou.

Para retomar o tema do autorrebaixamento presente tanto na vergonha quanto em certos casos de humilhação, podemos dizer: só há vergonha quando o sujeito assume internamente a sua desvalorização. Mesmo quando ela é imposta violentamente a partir de fora, o sujeito envergonhado procura se esconder do campo de visão do outro, porque sabe que sua simples presença pode produzir indignação diante do que ele se tornou após ser coberto pela vergonha. Ele pode então projetar no outro sua própria indignação.

Vejamos agora algumas características diferenciais do sentimento de humilhação. Humilhação implica violência (DE LA TAILLE, 2002, p.78), e violência, neste caso, intencional. O outro não é apenas uma projeção da minha indignação quanto à minha própria imagem, mas é a fonte de uma indignação que me toma a partir de fora. O sujeito se perde do lugar de origem de seu próprio rebaixamento. O outro, por algum motivo enigmático ou completamente fora do campo do sentido, é ativo em retirar coercitivamente os atributos narcísicos articulados a certos valores mantenedores da dinâmica do sujeito com seus ideais. Vergonha e humilhação coexistem quando a violência é extrema a ponto de o sujeito internalizar a imagem negativa imposta como se fosse a sua (DE LA TAILLE, 2002, p.78-79). 
Supomos que para a humilhação se tornar vergonha deve haver desequilíbrio entre a natureza da violência vinda do outro e as barreiras narcísicas capazes de proteger o sujeito de incorporá-la à sua própria identidade. O sentimento profundo de vergonha sentido por sobreviventes de campos de concentração evidencia a fragilidade dessas barreiras em situações extremas de violência. No outro lado da balança, percebemos que construções narcísicas frágeis podem favorecer experiências marcantes de humilhação consumada ou medo permanente de ser humilhado. Nestas situações, ser visto pelo outro pode equivaler a ser humilhado ou vir a ser humilhado pelo outro.

Examinemos o que Ciccone e Ferrant (2009) denominam vergonha de ser:

“O trauma narcísico primário relacionado à vergonha de ser é ligado à falha dessa função de eco e de 'espelho vivo'. O sentimento de continuidade narcísica apresenta um furo, se torna inconsistente. Nessa conjuntura, o objeto não foi 'psiquicamente ausente', foi ativamente desqualificante. A função espelho reenvia ao bebê que este está inteiramente preso a uma desqualificação de suas necessidades, isto é, de seu próprio ser. Pode-se dizer, nesse sentido, que a vergonha de ser é uma vergonha primária.” (CICCONE \& FERRANT, 2009, p.67-70)

Para estes autores, a vergonha de ser exprime um acontecimento tão primário que só o outro pode sentir vergonha. O sujeito se esconde, mas não consegue saber do que se esconde: ele sabe que o outro é capaz de humilhá-lo pelo simples fato de ser visto, mas perde o contato com o que sente, exprimindo apenas seu aspecto comportamental. Percebemos ressonâncias entre essa descrição e o que caracterizamos como humilhação. Como afirmamos anteriormente, várias formas de fragilidade narcísica podem contribuir para experiências de humilhação consumadas e sua repetição traumática ao longo da existência. Respeitando a suposição de externalidade da vergonha presente no conceito de vergonha de ser, encontramos na clínica sujeitos que não têm acesso ao sentimento de vergonha, mas somente à intenção humilhante vinda de fora. Sabem que o olhar do outro é perigoso, apesar de não saberem qual é o perigo.

Este é um ponto comum que aflige tanto tímidos embaraçados quanto tímidos humilhados. Ambos temem permanentemente o que o outro possa ver diante de sua imagem, sem representar — diferentemente do sujeito envergonhado - o que precisa permanecer escondido. Diante dessa impossibilidade de decidir, procuram se defender do olhar escondendo-se por inteiro. Mas enquanto o sujeito embaraçado coloca todas as suas fichas em seus sistemas de alarme, acreditando que estes poderão controlar minimamente a exposição e, por conseguinte, a consumação de uma vergonha insuportável, o sujeito humilhado já não alimenta essa esperança. Ele conhece a intenção do outro de humilhar, embora não consiga 
estabelecer qualquer narrativa que envolva a si como ponto de amarração dessa intenção. A única coisa que conhece do outro é a sua capacidade de humilhá-lo - uma capacidade de humilhação sem história. O si mesmo se torna "aquele que foi e será permanentemente humilhado”. As narrativas para essa humilhação são prosaicas, demonstrando certa pobreza na atitude predicativa do eu.

As queixas desses pacientes, a duras penas formuladas em análise, nos dão uma pálida ideia do sentimento de humilhação como resultado de parâmetros frágeis para dar contorno à localização de si diante do olhar. O significado particular com que usam a palavra "desconfiança” ou o modo como um deles descreve seu hábito de "estudar as pessoas" para formular julgamentos que, por vezes, se revelam precipitados e equivocados, expressa um tipo particular de relação com a alteridade. Esse hábito de estudo excessivo do outro, que toma por inteiro suas existências, os impede de se aproximar de outras pessoas, em decorrência do medo de se decepcionar com elas. Vivem para antecipar a possibilidade do pior.

Um matiz merece comentário: não se trata de um mecanismo obsessivo. A antecipação do pior é pura repetição da única experiência que encontra sentido em suas histórias, é o único saber que conseguem manejar. Sabem que, do outro, devem esperar o pior. Mais uma vez, aqui há pouco espaço para a dúvida e sua característica obsessiva. Ao examinarmos suas histórias, percebemos que nas suas relações mais iniciais o objeto não foi capaz de contribuir para a integração e a internalização de experiências vividas como violentas. $\mathrm{O}$ outro, externalizado e anônimo, se tornou uma mistura de receptáculo e fonte de toda a agressividade.

Um de nossos pacientes refere que as raízes de seu problema se estendem até situações de sua infância e adolescência, nas quais foi vítima de "racismo", de "rejeição" ou de "injustiças". A expressão racismo para qualificar as zombarias de colegas pelo fato de usar óculos demonstra a fragilidade de sua narrativa sobre seu sentimento de humilhação. Percebe a hostilidade contra um traço seu como algo que evocaria seu pertencimento a uma suposta raça. O racismo é, em seu vocabulário, uma palavra que aponta para o pior tipo de exclusão violenta vinda de um conjunto particular de seres humanos. Em seu caso, curiosamente, esta exclusão atingiria uma raça relacionada diretamente a um instrumento para poder ver o que os outros veem - a raça daqueles que não possuem a faculdade de enxergar e se proteger do que enxergam. Uma raça que, por outro lado, precisa de uma película para mediar o que se percebe do olhar que lhe é dirigido.

O paciente associa mais tarde que raízes anteriores de seu sentimento de humilhação remetem a ter nascido com problemas na visão. Acredita que este era o motivo para a rejeição por parte de crianças que se recusavam a brincar ou estar com ele. Em ambas as situações mencionadas, percebemos sua solidão ao enfrentar experiências de rejeição e exclusão. O sentimento permanente 
de humilhação é o único resquício de um tipo de relação em que o objeto se ausentou de sua função de mediação e foi ativamente desqualificante.

A título de recapitulação: ao contrário da vergonha — quando "outro com intenção de rebaixar" nem sempre existe — na humilhação há sempre esse outro. É comum a associação entre vergonha e humilhação se o sujeito humilhado internalizar os valores de quem o humilhou. Nesse caso, o sujeito humilhado aceita a imagem negativa imposta a partir de fora, de forma violenta. Se na vergonha algo é desnudado em função de alguma ação ou característica do sujeito, na humilhação essa interioridade exposta é arrancada violentamente, rompendo a dimensão de segredo, fundamental para a relação com o outro.

Para compreendermos melhor como o olhar do outro traz permanentemente o risco de romper a dimensão do segredo, constituinte no psiquismo da construção da interioridade, passemos ao exame da transparência psíquica.

\section{A TRANSPARÊNCIA PSÍQUICA}

Numa primeira pesquisa clínica, que incidiu sobre a clínica de sujeitos melancólicos e outros sujeitos portadores de lúpus eritematoso sistêmico em atendimento analítico (VERZTMAN \& PINHEIRO, 2012), já era evidente o tema da transparência subjetiva como índice de fragilidade narcísica. Os sujeitos melancólicos estavam vinculados a um ideal de transparência que apareceu sob a forma da aspiração a uma linguagem unívoca, límpida e assim transparente para qualquer um que se utilizasse de seus signos. Este era o aspecto linguístico da transparência. Outro aspecto - que podemos denominar imagético - do ideal de transparência ocorreu sob a forma da evocação de imagens para o analista que não comportassem enganos, numa situação na qual seria impossível os dois não enxergarem a mesma imagem do mesmo modo.

Podemos dar como exemplo desta aspiração à transparência a fala de um paciente melancólico (VERZTMAN, 2012): “A verdade é uma só, como uma identidade, um rótulo num pote em que está escrito - açúcar”. Este mesmo paciente, no primeiro encontro com sua analista, trouxe consigo uma pasta contendo receitas médicas, exames laboratoriais, textos de jornal e muitos outros documentos. Ali ele dizia que "estava tudo seu" (devidamente catalogado), "a história”, e apontava para a importância da sua ciência sobre o que trazia. Ele precisava se assegurar de que sua analista ia "olhar" para tudo aquilo, pois tinha uma necessidade (embora com pouca esperança de realizá-la) de "ser visto como um todo”. É somente ao se tornar transparente que ele adquire alguma confiança em ser percebido. Ele só podia acreditar no que percebia de si mesmo se sua analista olhasse para “a história” exatamente do mesmo modo que ele. 
Percebemos outro aspecto da aspiração à transparência - o qual podemos denominar aspiração a ser visto por dentro — nesta passagem do tratamento de uma paciente lúpica (VERZTMAN \& PINHEIRO, 2012) Ela pergunta à sua analista: "A senhora está notando alguma coisa?". Visivelmente decepcionada pelo fato de a analista não conseguir notar o que ela desejava que tivesse sido percebido, a paciente arregaçou as mangas da blusa e exibiu o punho até então coberto, dizendo: "perdi o meu relógio". A paciente em questão estava testando a capacidade da analista de ver o que os olhos não podiam ver. E de ver o que não podia ser visto. A visão estava pouco integrada a outras dimensões capazes de conferir existência a algo tão complexo como ter um interior. Apenas se os limites do corpo não fossem barreira ao olhar, a existência desse espaço interior invisível poderia estar assegurada.

É importante notar que a aspiração à transparência nestas formas distintas não se relaciona com a emergência de angústia ou significa qualquer tipo de ameaça. A aspiração à transparência é um apelo ao reconhecimento do outro, expressa a esperança de vir a ser percebido. Isto não ocorrerá do mesmo modo na timidez.

"A timidez, essa angústia social, indica que todos ficam sempre informados. O ser é transparente sob o olhar do outro; o castigo está a caminho, apenas a fuga pode salvar [...]. Como cada um de nós já notou, não há algo mais visível que um tímido. Enrubescendo, gaguejando, fugindo ou procurando a melhor a melhor tática de evitar os encontros [...].” (AVRANE, 2007, p.143. Tradução livre)

Entre os tímidos há também um desejo de transparência e um ideal de transparência, construídos na relação com adultos privilegiados, em relação aos quais a barreira do olhar estaria esmaecida. Uma paciente afirma não ter segredos com sua mãe. Ela e sua mãe dormem na mesma cama, apesar de a paciente ter seu próprio quarto. Há um pequeno detalhe na ausência de segredos entre as duas: ela nos informa não conseguir esconder nada da mãe; diz que ficaria muito aflita caso guardasse algum segredo.

É nessa relação de transparência mútua que ela encontra alguma segurança. Segurança baseada na submissão à necessidade da mãe de conhecê-la "por dentro e por fora”. Segurança de um olhar penetrante que a protege, ao preço de ser sua única garantia contra os riscos de outro olhar que, encontrando barreiras para enxergá-la por inteiro, pode acabar por humilhá-la ou ridicularizá-la. Desse modo, ao contrário dos pacientes de nossa pesquisa anterior, já referidos, os tímidos (sobretudo os que sofrem de embaraço) foram alvo de uma promessa: se estes adultos pudessem ver através deles algo que ninguém mais poderia ver, a segurança desse olhar privilegiado os protegeria dos perigos do olhar externo. 
O investimento desejante do outro tem no ideal de transparência sua forma mais acabada de perfeição narcísica. Para ser desejado pelo outro é preciso ser transparente ao seu olhar. Há uma confluência entre o campo do desejo e o fato de ser permanentemente observado. É através desta forma particular de investimento escópico que o tímido encontra algum parâmetro para a experiência de ser desejado. Note-se que ao contrário do sujeito melancólico, o sujeito tímido foi alvo de maciço investimento parental. É fácil perceber que logo esse idílio de comunhão de olhares vai encontrar seu fim: o olhar do outro vai se bifurcar entre uma função protetora já descrita e uma função persecutória. O perigo da mirada alheia será cada vez mais experimentado.

A impossibilidade cada vez maior de contar com a função protetora do olhar do adulto privilegiado faz com que a sensação de transparência do tímido se espraie pelo mundo, expressando ao mesmo tempo anseio de amor exclusivo do outro e receio intenso de que o outro não corresponda a esse anseio, rejeitando-o e humilhando-o.

Outra paciente diz que tem muito a dizer, o que infelizmente não consegue, sobretudo na presença de mais de uma pessoa. Este aspecto é frequente entre os tímidos. O olhar de “mais de um” os dilacera. Segundo seu relato, ninguém diria que ela é inteligente apenas observando-a, o que ela de fato aguarda. Ela suplica pela segurança de uma mirada que extraísse os seus atributos ideais de uma só vez. Ao invés disso, a opacidade do olhar alheio comum, "a outra pessoa, o mais de um”, a reenvia para o abismo. Na sala de aula, é como se estivessem olhando para ela e pensando: “coitada, ela não consegue”, “o que ela está dizendo?! Não dá para entender nada!”, “quem ela pensa que é?!”. O outro privilegiado não foi capaz de manter sua promessa.

A distância cada vez mais sentida entre proteção pela transparência e a experiência de extensão da transparência a qualquer olhar faz com que o outro "mais de um" se torne cada vez mais um estranho, a quem não posso conhecer, mas que pode (isto é sempre uma pergunta, raramente uma certeza) me conhecer inteiramente na minha transparência e, assim, me julgar.

O tímido se vê permanentemente como um réu num suposto "tribunal do olhar” (AVRANE, 2007, p.160) e evita dar provas aos promotores de que há algo abjeto em seu interior. "Ao tribunal do olhar, o tímido é convidado sem cessar. Suas confissões se tornam um pleito [...]. Tanto as figuras mostradas quanto os gestos ou textos expostos os colocam em evidência. As estratégias não são iguais, mas a necessidade de um julgamento pelo olhar é absoluta” (idem, ibidem. Tradução livre).

O tribunal, entretanto, ocupa cada vez mais espaço em seu mundo e um perigo deve ser fonte de suas precauções: o perigo de ser descoberto. A angústia antecipatória do tímido (PACHECO-FERREIRA, 2012) é fonte privilegiada 
de mal-estar, uma vez que ele não tem como saber o que deve esconder. Esta forma particular de angústia, como Freud já sublinhara (1917/1993), é uma medida protetora. Está conjugada à necessidade de se mostrar incessantemente e conhecer todos os detalhes do modo como recebe o retorno deste olhar. É também uma forma de apelo desesperado ao reconhecimento: "A timidez cede lugar em seguida à provocação, isto é, a uma forma de procurar no olhar do outro o reconhecimento e nele encontrar a imagem esperada" (AVRANE, 2007, p.161. Tradução livre).

Esta provocação, sempre fracassada, expressa dois sentidos para a transparência psíquica: ser inteiramente acessível à percepção do outro ou, ao contrário, ser invisível.

"O sujeito deseja ser reconhecido como objeto de investimento do outro, teme, porém não possuir os predicados que o outro, supostamente, desejaria que ele tivesse. Resultado: nem quer ser visto nem quer deixar de ser visto. O paradoxo é o cerne do sujeito envergonhado" (COSTA, 2012, p.12).

\section{PARA CONCLUIR}

Procuramos demonstrar, por meio do exemplo do sujeito dito 'tímido', que há todo um universo do olhar a ser explorado pela clínica psicanalítica contemporânea. O tímido testemunha a hipertrofia do campo escópico, produzindo certos tipos de sofrimento que qualificamos como embaraço, humilhação e transparência psíquica. Estas modalidades de padecimento interrogam diretamente os limites do olhar para mediar de modo absoluto a relação com a alteridade. Cabe aos psicanalistas descobrir, na clínica singular de cada um, meios de alcançar alguma relativização para o peso da mirada alheia.

Recebido em 15/1/2014. Aprovado em 17/2/2014.

\section{REFERÊNCIAS}

AUlAGNiER, P. (1990) "O direito ao segredo: Condição para poder pensar”, in Um intérprete em busca de sentido. São Paulo: Escuta. (2007) Les timides. Paris: Seuil.

CICCONNE, A. \& FERRANT, A. (2009) Honte, culpabilité et traumatisme. Paris: Dunod.

COSTA, J. F. (2012) “Os sobrenomes da vergonha: depressão e narcisismo”, in Sofrimentos narcísicos. Rio de Janeiro: Cia de Freud. 
DE LA TAILLE, I. (2002) Vergonha: a ferida moral. Petrópolis: Vozes.

EHRENBERG, A. (1998) La Fatigue d'être soi. Paris: Odile Jacob.

FREUD, S. (1917/1993) "Duelo y melancolia", in Obras completas, v.XIV. Buenos Aires: Amorrortu.

GIDDENS, A. (2002) Modernidade e identidade, Rio de Janeiro: Jorge Zahar Editor.

GOUlejAC, V. (1996) Les sources de la honte. Paris: Desclée de Brouwer.

GREEN, A. (2003) Énigmes de la culpabilité, mystère de la honte. Révue Française de Psychanalyse: Honte et culpabilité, n.LXVII. Paris: PUF.

McDOUGALL, J. (1992) Scènes de la vie primitive. Nouvelle Revue de Psychanalyse. Paris, n.46, p.139-149.

MILLER, J. A. (2003) Notes sur la honte. Revue de la Cause freudienne, n.54.

PACHECO-FERREIRA, F. (2012) Algumas questões sobre a angústia e sua relação com a vergonha, in VERZTMAN, J, HERZOG, R., PINHEIRO, T. \& PACHECO-FERREIRA, F. (Orgs.). Sofrimentos narcísicos. Rio de Janeiro: Cia de Freud, p.165-184.

PINHEIRO, T., VERZTMAN, J, VENTURI, C \& BARBOSA, M. (2006) Por que atender fóbicos sociais: justificativa de uma pesquisa clínica. Psicanalisar hoje. Rio de Janeiro: Contracapa.

PONTALIS, J.- B. (1991) Non, deux fois non: Tentative de définition et de démantelement de la réaction thérapeutique négative, in Perdre de vue. Paris: Gallimard, p.73-99.

TISSERON, S. (1992) La honte — Psychanalyse d'un lien social. Paris: Dunod.

VENTURI, C \& VERZTMAN, J. Interseções da vergonha na cultura, na subjetividade e na clínica atual, in VERZTMAN, J., HERZOG, R., PINHEIRO, T. \& PACHECO-FERREIRA, F. (Orgs.). Sofrimentos narcísicos. Rio de Janeiro: Cia de Freud, 2012, p.119-146.

VERZTMAN, J. S.; HERZOG, R.; PINHEIRO, T. (2009). Vergonha, culpa, depressão contemporânea e perdão. Trivium. Rio de Janeiro: Online, v.1, p.1-5.

\& PACHECO-FERREIRA, F. J. (2012) Sofrimentos narcísicos. Rio de Janeiro: Companhia de Freud.

\& PINHEIRO, T. (2012) Corpo, tempo e transferência numa pesquisa clínica, in HERZOG, R., PACHECO-FERREIRA, F., PINHEIRO, T. \& VERZTMAN, J. (Orgs.). Sofrimentos narcísicos. Rio de Janeiro: Cia de Freud, 2012, p.49-96.

(2005) Vergonha, honra e contemporaneidade. Pulsional Revista de Psicanálise, v.VIII, n.181. São Paulo, p.88-100.

. (2011) Freud e a vergonha. Cadernos de Psicanálise - SPCRJ, v.27.

Rio de Janeiro: SPCRJ, p.73-99.

A melancolia e o olhar: uma clínica contemplativa?, in COELHO

JR., N., SALÉM, P.KLAUTAU, P. (Orgs.) Dimensões da intersubjetividade. São Paulo: Escuta/Fapesp, 2012, v.1, p.105-124.

ZYGOURIS, R. (1995) “A vergonha de si”, in Ah! As belas lições! São Paulo: Escuta, p.42-67.

Julio Verztman

jverztman@globo.com 